\title{
Retention of pain neuroscience knowledge: a multi-centre trial
}

\author{
Adriaan Louw PT, PhD \\ International Spine and Pain Institute, Story City, lowa, USA
}

Kory Zimney PT, DPT

University of South Dakota, School of Health Sciences; Department of Physical Therapy, Vermillion, South Dakota, USA

Emilio "Louie" Puentedura PT, DPT, PhD

University of Nevada Las Vegas, School of Allied Health Sciences, Department of Physical Therapy, Las Vegas, Nevada, USA

\section{ABSTRACT}

Pain Neuroscience Education (PNE) has been shown to increase patient and healthcare provider knowledge of pain. To date, however, no study has examined if that knowledge is maintained over time. Patients suffering from chronic pain were invited to attend a free PNE lecture. Patients were required to complete intake demographics followed by two self-report measures 2 weeks before, 48 hours before, 48 hours after, 6 weeks after and 12 weeks after the PNE lecture. The two self-report measures collected at each interval were pain ratings (numeric rating scale [NRS]) and knowledge of pain (Neurophysiology Pain Questionnaire [NPQ]). Only data from patients who completed these measures at each interval were analysed. A repeated ANOVA was used to analyse the changes in NRS and NPQ over time. Forty-seven patients (11.4 years of pain) completed all five surveys for analysis. The NPQ scores showed significant increases in pain knowledge from 2 weeks pre-PNE to all post-PNE intervals $(p=0.002, p=0.001, p=0.005), a s$ well as 48 hours pre-PNE to all post PNE-intervals ( $p=0.001, p<0.001, p=0.001)$. A single PNE session has the ability to increase pain knowledge, and maintain the increased knowledge 3 months later.

Louw A, Zimney K, Puentedura E (2016) Retention of pain neuroscience knowledge: a multi-centre trial. New Zealand Journal of Physiotherapy 44(2): 91-96. doi: 10.15619/NZJP/44.2.04.

Key words: Pain, Neuroscience, Education, Knowledge, Retention

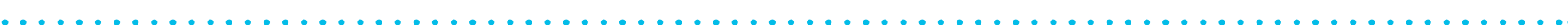

\section{INTRODUCTION}

Teaching people about the neurobiology and physiology of pain has gained popularity in physiotherapy in recent years (Nijs et al 2011, Nijs and Van Houdenhove 2009). This approach of teaching people more about the biology and physiology of a pain experience is referred to as pain neuroscience education (PNE) (Louw et al 2015a, Louw and Puentedura 2014, Zimney et al 2014). For people suffering from persistent pain, several randomised controlled trials and a systematic review have reported compelling evidence for PNE having a positive effect on pain, function, pain catastrophisation and physical movement (Louw et al 2011, Moseley et al 2004, Moseley 2002). For more acute and sub-acute conditions, a recent multi-centre randomised controlled trial of PNE provided preoperatively for lumbar surgery reported a significant reduction in healthcare utilisation at 1-year follow-up, as well as superior surgical experience from the patient's perspective (Louw et al 2014a).

In lieu of the positive outcomes associated with PNE, various authors have proposed different mechanisms behind the success of PNE (Meeus et al 2010, Moseley 2003a, Moseley et al 2004). Some authors have argued that PNE reduces fear, which in turn leads to improved movements, function and a decreased pain experience (Moseley et al 2004). Moseley (2002) argued that PNE's proposed success may be associated with a reconceptualisation of pain by the patient. This reconceptualisation dichotomises tissue issues (nociception) and pain, thus helping patients understand that tissue injury and pain are not synonymous (Nijs et al 2013, Puentedura et al 2009). Furthermore, it has been argued that one of PNE's benefits may be associated with a "new" pain language which utilises fewer provocative words, thus decreasing the pain experience (Louw et al 2013a, Louw et al 2014b). Louw et al (2015a) showed that PNE provided prior to lumbar surgery resulted in patients having a more realistic expectation about pain after surgery, and helped them appreciate that pain is a normal part of the human experience.

Although these studies all argue various aspects of the proposed mechanism behind PNE's success, all of the studies assume that patients' understanding and knowledge of pain has increased. In 2003, Moseley (2003b) conducted a study whereby he used a Neurophysiology of Pain Questionnaire (NPQ) to measure if patients and healthcare providers indeed experienced an increase in knowledge of pain, following a 3 hour PNE lecture. The results from 276 patients with chronic pain and 288 healthcare providers showed that following a PNE lecture, both patients and healthcare providers had an increased knowledge of pain (patients improved by $32 \%$; healthcare providers $23 \%$ ). To date, however, no studies have tested if NPQ increases following an initial PNE presentation are sustained when measured at a later interval. The purpose of this study was therefore to examine if an increased knowledge of pain neuroscience is maintained after an initial pain neuroscience educational session. 


\section{METHODS}

\section{Study design}

This was a multi-centre trial. All participants acknowledged their understanding and willingness to participate by providing signed consent. Prior to the study, ethics approval was obtained. Participants were informed that the study was aimed at measuring their level of pain before and after a communitybased lecture on PNE. Participants were blinded to the true purpose of the study, i.e. retention of pain neuroscience knowledge.

\section{Setting}

An educational seminar company specialising in PNE for physiotherapists secured large auditoriums in three different cities for the study. One venue was a hotel conference room and the other two were physiotherapy school auditoriums. Each facility was disability accessible, with overhead sound, a projections screen and projector.

\section{Participants and recruitment}

Brochures advertising the event were sent to physiotherapists in the seminar company's database who worked in the three designated cities. Physiotherapists were alerted to the event and asked to encourage current or past patients with chronic pain to attend the 2 hour evening lecture. The brochures indicated that the physiotherapists in the area would be hosting a free 2-hour evening lecture on the latest understanding of pain and feature a pain specialist. The brochures encouraged anyone currently experiencing chronic pain and interested in knowing more about "how pain works" to attend. No specific exclusions were listed in regards to diagnoses, duration of pain, and location of pain, gender, age or ethnicity, except the disclaimer that the presentation was being delivered in English. Family members interested in attending were allowed to attend the lectures. Even though the presentations were free, interested patients were asked to sign up for the event, allowing organisers to mail attendees details about the evening lecture (location, date, times) and allowing the researchers to send a letter to each patient inviting them to be part of the study. The letter explained that participation in the study was completely voluntary and their participation would not be reported to any healthcare provider. Additionally, participants were informed that the speaker of the event would be blinded to their being part of the study or not. The letter informed attendees they would be required to complete two questionnaires at five different intervals ( 2 weeks before; 48 hours before; 48 hours after; 6 weeks after and 12 weeks after) (Figure 1). Participants were furthermore informed that those who participated in the study and completed the questionnaires at all of the five intervals would be compensated for their time with a gift card.

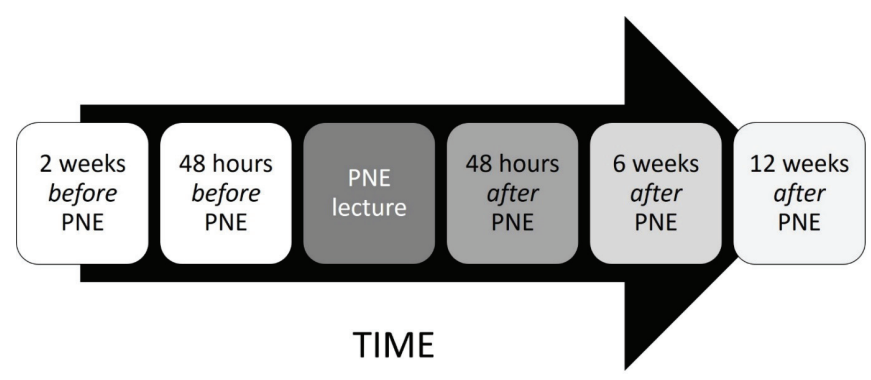

Figure 1 Study timeline

Notes: PNE, Pain Neuroscience Education.

\section{Intervention}

The content of PNE is well documented and in line with other studies (Louw 2014, Louw et al 2013a, Moseley 2003b, Zimney et al 2014). The 2-hour PowerPoint presentation's main themes included a discussion of peripheral sensitisation, central sensitisation, bio-psycho-social factors associated with chronic pain, immune responses in pain, threat appraisal of the brain, the pain neuromatrix, nociception, somatosensory cortex changes and pain, stress and endocrine responses in pain as well as various therapeutic strategies to ease pain (Louw 2014, Louw et al 2013a, Moseley 2003b, Zimney et al 2014). Various images, metaphors and examples were used to convey the PNE to the attendees (Louw 2013). Notepads and pens were provided for patients to take notes. A small summary booklet was provided to each participant upon completion of the lectures. Following the formal presentation, participants were encouraged to ask questions. The presentation did not specifically address or target any questions contained in the NPQ.

\section{Outcome measures}

Participants interested and willing to participate completed a demographic survey capturing their age; gender; duration of pain; height; weight; and location of their pain. Additionally, participants were asked to complete two self-report outcome measures:

- Pain: Pain was assessed using the Numeric Pain Rating Scale (NRS), as has been used in various PNE studies measuring pain outcomes (Moseley 2003a, Moseley 2005, Moseley 2002). The minimal detectable change (MDC) for the NRS is reported to be 2.1 (Cleland et al 2008).

- Pain Knowledge: Pain knowledge was measured using the NPQ. The NPQ is based on a current pain science text (Wall and Melzack 1999) and was used in a previous study measuring the neurophysiology knowledge of patients and healthcare personnel (Moseley 2003b). The NPQ is a 19-point questionnaire requesting 'true'; 'false'; or 'not sure' answers to statements, with higher scores indicating more correct answers. The questionnaire used in this study was similar to the one used by Moseley (2003b) and adapted slightly to make it easier for patients to understand, e.g., "nociception" was replaced with "danger messages." Since the development of the NPQ a statistical analysis of the NPQ has led to the development of an abbreviated NPQ which removed ambiguous questions (Catley et al 2013). The revised NPQ was not available by the time this trial started. 
At the designated timed intervals (Figure 1), participants were sent online links and reminders (Surveymonkey) (George et al 2013) to complete the NRS and NPQ. The demographic sheets were only to be completed at the initial survey starting point 2 weeks before the lecture. Reminders and links were e-mailed to patients 48 hours prior to, 48 hours after, 6 weeks after and 12 weeks after the PNE presentation. All e-mail links and e-mail correspondence with participants were performed by an independent research assistant and none of the primary investigators.

\section{Data analysis}

All data were analysed using SPSS version 22.0 (SPSS Inc., Chicago, Illinois, USA). Level of significance was set at $\mathrm{a}=0.05$. To determine whether there were any significant differences in NPRS and NPQ at each time point, a repeated measures ANOVA (five time points) was conducted for each of the dependent variables (NRS and NPQ). If an interaction was observed then simple main effects were tested, with appropriate Bonferroni correction.

\section{RESULTS}

\section{Patients}

Figure 2 provides a flow chart of the study. Out of 228 eligible patients with chronic pain, only 132 (57.9\%) indicated they were willing to participate by completing the initial intake forms; NRS and NPQ 2 weeks before the PNE Education session. Of the 132 entered into the study, 85 failed to complete postPNE outcome measures from at least one follow up time point leaving us with viable data from only 47 participants. Analysis for this study was therefore based on data from 47 participants (Table 1), with a mean age of 56.5 years and a mean duration of pain of 11.4 years.

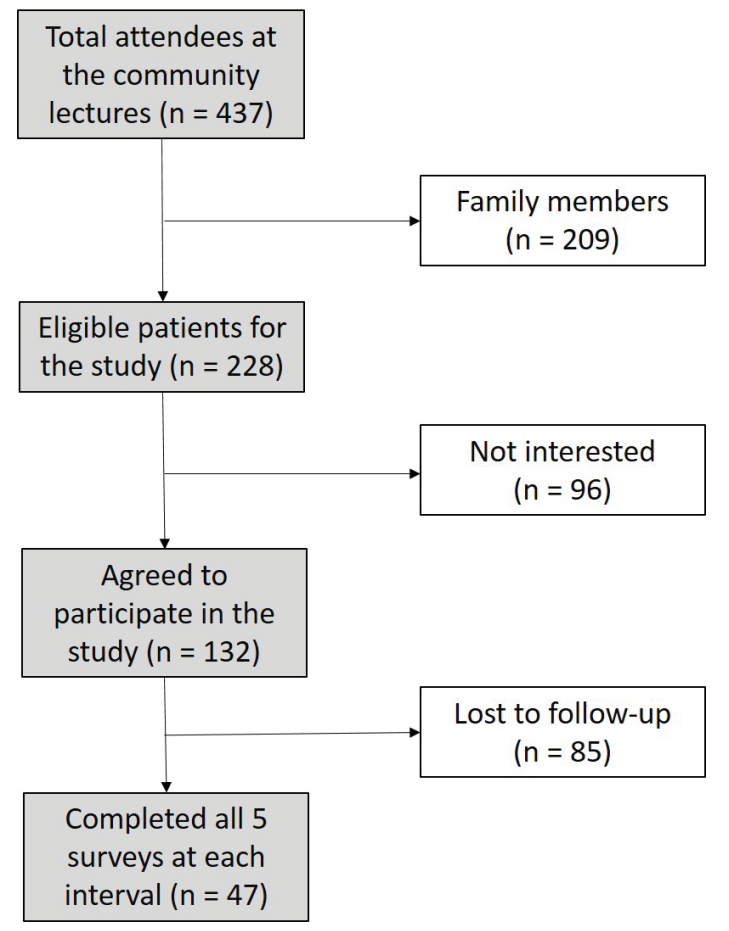

Figure 2 Study flow sheet
Table 1 Demographic information for study participants

\begin{tabular}{|c|c|}
\hline Characteristics & Results \\
\hline Age (mean (standard deviation) years) & 56.5 (SD 10.64) \\
\hline Sex & $\begin{array}{l}37 \text { females } \\
(78.7 \%)\end{array}$ \\
\hline $\begin{array}{l}\text { Duration of symptoms (mean (standard } \\
\text { deviation) years) }\end{array}$ & $11.4(S D 11.86)$ \\
\hline Pain rating (mean NRS) & 5.02 \\
\hline Pain knowledge (mean NPQ (frequency)) & $8.86(46.6 \%)$ \\
\hline Height (mean; cm) & $168.4(S D 9.5)$ \\
\hline Weight (mean; kg) & $85.55($ SD 22.27) \\
\hline Highest rated areas affected by pain & $\begin{array}{l}\text { Low Back 55.3\% } \\
\text { Lower Legs } 46.8 \% \\
\text { Neck } 40.4 \% \\
\text { Hips } 31.9 \% \\
\text { Upper Back } 29.8 \%\end{array}$ \\
\hline
\end{tabular}

Notes: NRS, Numeric Pain Rating Scale; NPQ, Neurophysiology Pain Questionnaire

\section{Pain knowledge}

The pre and post-PNE NPQ scores are found in Figure 3 and Table 2. The NPQ scores showed significant increases in pain knowledge from 2 weeks pre-PNE to all post-PNE intervals, as well as 48 hours pre-PNE to all post PNE-intervals. During the control period (no PNE), from 2 weeks prior to PNE to 48 hours pre-PNE, there was no statistical difference in pain knowledge $(p=0.46)$. Immediate post PNE NPQ scores remained similar to scores at 6 and 12 weeks post-PNE ( $p=1.00$ and $p=0.55$ respectively).

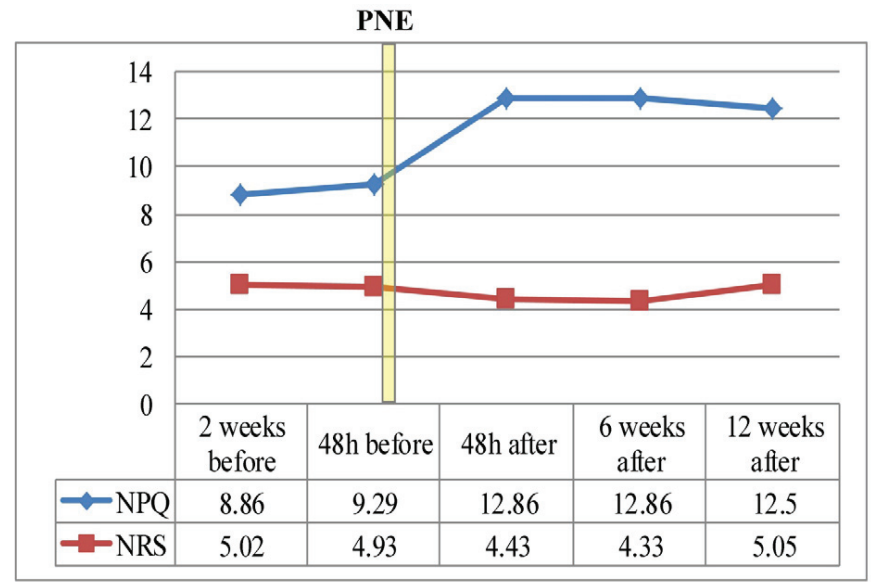

Figure 3 NPQ and NRS data at each intake interval

Notes: NPQ, Numeric Pain rating Scale; NRS, Numeric Pain Rating Scale; PNE, Pain Neuroscience Education 
Table 2 NPQ differences for the timed intervals

\begin{tabular}{|c|c|c|c|c|c|}
\hline 2 weeks before & 48 hours before & 48 hours after & 6 weeks after & 12 weeks after & Difference \\
\hline 8.86 & 9.29 & & & & $p=0.463$ \\
\hline 8.86 & & 12.86 & & & $p=0.002 *$ \\
\hline 8.86 & & & 12.86 & & $p=0.001$ * \\
\hline \multirow[t]{7}{*}{8.86} & & & & 12.5 & $p=0.005^{*}$ \\
\hline & 9.29 & 12.86 & & & $p=0.001$ * \\
\hline & 9.29 & & 12.86 & & $p<0.001$ * \\
\hline & 9.29 & & & 12.5 & $p=0.001$ * \\
\hline & & 12.86 & 12.86 & & $p=1.000$ \\
\hline & & 12.86 & & 12.5 & $p=0.545$ \\
\hline & & & 12.86 & 12.5 & $p=0.560$ \\
\hline
\end{tabular}

Notes: *, statistically significant

Pain

The NRS scores at each interval are found in Figure 3. There were significant differences in pain (NRS) between 2 weeks before and 6 weeks after $(p=0.02), 48$ hours after and 12 weeks after $(p=0.03)$ and between 6 weeks after and 12 weeks after $(p=0.03)$, but the differences did not meet the minimal detectable change of 2.1 .

\section{DISCUSSION}

This is the first study to show that a single PNE session for people in chronic pain has the ability to increase pain knowledge, and this increased pain knowledge remains intact three months following the single educational intervention.

It can be argued that for PNE to be effective patients need to receive the message, internalise the message and then apply it to their current pain experience. This premise is the fundamental underpinning of deep learning (Sandberg and Barnard 1997, Wittmann-Price and Godshall 2009). Various studies discussing behaviour change call for deep learning whereby patients indeed need to be exposed to a conceptual change, with application of the information to their situation, and the message must be carried away with them to allow true change (Crabtree et al 2001). In contrast, it is argued that a main reason why healthcare education fails is because of superficial learning. In superficial learning, a patient receives the message, but the message is not internalised and applied to the healthcare issue, thus eroding over time. Although various factors such as motivation, social and environmental influences, all play a role in deep learning (Sandberg and Barnard 1997, WittmannPrice and Godshall 2009), it can be argued that a fundamental starting point has to be a gained knowledge of the healthcare information imparted by the healthcare provider and this information should not erode over time. To prevent the erosion of gained information, various strategies such as follow-up phone calls; websites with information; and providing a handout of the educational material can be implemented (Cherkin et al 1996, Louw et al 2013b, Oshodi 2007). In regards to PNE and physiotherapy, this is the first study to report that gained PNE knowledge immediately after a single PNE educational session remains intact three months later.
The results from this study warrant an investigation as to why the gained knowledge remained intact three months later, in comparison to various studies reporting a typical erosion effect with single-educational-design interventions. One argument is the interest in pain by people suffering from pain (Louw et al 2009). Various authors have implied that the current models used to teach people about pain are inadequate (Gifford 1998, Moseley 2007, Nijs et al 2013). In orthopaedics, as an example, as a means to explain pain to a patient, healthcare providers often migrate towards biomedical models such as anatomy and biomechanics. Not only have these models been shown to be unhelpful in understanding why they hurt, but they also induce fear and anxiety in patients (Sloan and Walsh 2010). PNE by definition aims to reconceptualise pain, thus minimising biomechanical and anatomical issues as a main source of pain, and rather focuses on the biological processes associated with persistent pain, such as central sensitisation (Moseley 2007). Given that this cohort of participants comprised a seasoned chronic pain population with a mean duration of pain over 11 years, it could be argued they were seeking a new paradigm to understand why they still hurt. Participants were clearly engaged and interested in the material, since their knowledge of pain neurophysiology increased by $38 \%$, which correlates well with the $32 \%$ reported by Moseley (2003b).

To date, no study has shown that an increase in NPQ is correlated to decreased pain. In fact, a recent case series of patients preparing for lumbar surgery (Louw et al 2015a), as well as a single-case functional magnetic resonance imaging (fMRI) study (Louw et al 2015b), showed that immediately after PNE, patients often have a small increase in their pain, often clinically referred to as "explain pain pain." Educational theorists believe this slight increase may in fact be a sign of deep learning, indicating patients received the message and internalised it, which may lead to an emotional response. The fact that pain in itself was not meaningfully changed at any interval after PNE is not surprising. In people with chronic pain there are various biological changes associated with an increased pain experience as a means to protect (Woolf 2007, Woolf and Salter 2000). These changes are often either irreversible or likely to take a long time to change, allowing pain 
to ease. This belief is underscored by the fundamental premise of cognitive behavioural therapy that aims to improve function despite pain (Nijs et al 2012, Ostelo et al 2003). In a recent multi-centre randomised controlled trial, Louw et al. showed that after low back surgery, patients who received PNE prior to surgery had similar back and leg pain ratings one year after surgery, but despite the pain, spent $45 \%$ less on healthcare in the 1 year after surgery and rated their surgery as a success, when compared to patients who did not receive PNE (Louw et al 2014a). The results from these studies, along with this study's results, may in fact indicate that pain ratings may not be an appropriate indication of success of PNE. PNE reconceptualises pain and aims to help patients understand that pain is not an indication of the health of their tissues.

\section{Limitations}

This study contains various limitations. Only patients with access to the Internet, ability to attend an evening lecture, and to listen to and speak the English language were able to participate. In addition, only 47 out of 132 (35.6\%) of the attendees consenting to participate ended up completing all of the necessary surveys at follow-up. The high loss to follow-up may have potentially skewed the results. Finally, we also cannot discount the possibility that the NPQ may have served as a refresher to the pain education material and therefore, had an impact on results.

\section{CONCLUSION}

A fundamental cornerstone of PNE is gained knowledge of pain science. PNE is able to increase people in pain's knowledge of pain, according to modern pain science, and this enhanced knowledge of pain remains intact three months after a single educational intervention.

\section{KEY POINTS}

1. Pain neuroscience education (PNE) is able to increase a person's knowledge of pain.

2. The increase in pain knowledge following a PNE session is maintained three months after the PNE session.

3. Although PNE increases pain knowledge and is maintained three months later, it does not lead to decreased pain ratings.

4. The ability to produce a gained knowledge of pain with a PNE lecture can be replicated in a multi-centre approach, thus providing the potential for large scale therapeutic educational approaches to help people suffering from persistent pain.

\section{PERMISSIONS}

The study was approved by the Internal Review Board (IRB) / Ethics at Southwest Baptist University in Bolivar, MO. Patients provided written consent to participant in the study.

\section{DISCLOSURES}

The authors affirm that they have no financial affiliation (including research funding) or involvement with any commercial organisation that has a direct financial interest in any matter included in this manuscript. The authors do receive royalties for patient books on pain. A full disclosure was provided at the start of the PNE lecture and no teaching material referred to any of the patient books.

\section{ADDRESS FOR CORRESPONDENCE}

Adriaan Louw, International Spine and Pain Institute, PO Box 232, Story City, lowa, USA, 50248. Telephone: 1-515-722-2699. E-mail: Adriaan@ispinstitute.com

\section{REFERENCES}

Catley MJ, O'Connell NE, Moseley GL (2013) How good is the neurophysiology of pain questionnaire? A Rasch analysis of psychometric properties. The Journal of Pain 14(8);818-827. doi: 10.1016/j. jpain.2013.02.008.

Cherkin DC, Deyo RA, Street JH, Hunt M, Barlow W (1996) Pitfalls of patient education: limited success of a program for back pain in primary care. Spine 21(3):345-355.

Cleland JA, Childs JD, Whitman JM (2008) Psychometric properties of the Neck Disability Index and Numeric Pain Rating Scale in patients with mechanical neck pain. Archives of Physical Medicine and Rehabilitation 89(1):69-74. doi: 10.1016/j.apmr.2007.08.126.

Crabtree JL, Royeen CB, Mu K (2001) The effects of learning through discussion in a course in occupational therapy: a search for deep learning Journal of Allied Health 30(4):243-247.

George DR, Dreibelbis TD, Aumiller B (2013) Google Docs and SurveyMonkey: lecture-based active learning tools. Medical Education 47(5):518. doi: 10.1111/medu.12172.

Gifford L (1998) Pain, the tissues and the nervous system: A conceptual model. Physiotherapy 84(1):27-36. doi: 10.1016/S0031-9406(05)65900-7.

Louw A (2013) Why Do I Hurt? A Neuroscience Approach to Pain. Minneapolis: OPTP.

Louw A (2014) Therapeutic neuroscience education via e-mail: a case report. Physiotherapy Theory and Practice 30(8):588-596. doi: 10.3109/09593985.2014.912255.

Louw A, Butler DS, Diener I, Puentedura EJ (2013a) Development of a preoperative neuroscience educational program for patients with lumbar radiculopathy. American Journal of Physical Medicine and Rehabilitation 92(5):446-452. doi: 10.1097/PHM.0b013e3182876aa4.

Louw A, Diener I, Butler DS, Puentedura EJ (2011) The effect of neuroscience education on pain, disability, anxiety, and stress in chronic musculoskeletal pain. Archives of Physical Medicine and Rehabilitation 92(12):2041-2056. doi: 10.1016/j.apmr.2011.07.198.

Louw A, Diener I, Butler DS, Puentedura EJ (2013b) Preoperative education addressing postoperative pain in total joint arthroplasty: review of content and educational delivery methods. Physiotherapy Theory and Practice 29(3):175-194. doi: 10.3109/09593985.2012.727527.

Louw A, Diener I, Landers MR, Puentedura EJ (2014a) Preoperative pain neuroscience education for lumbar radiculopathy: a multicenter randomized controlled trial with 1-year follow-up. Spine 39:18 14491457. doi: 10.1097/BRS.0000000000000444.

Louw A, Diener I, Puentedura E (2014b) Comparison of terminology in patient education booklets for lumbar surgery. International Journal of Health Sciences 2(3):47-56. doi: 10.15640/ijhs.v2n3a5.

Louw A, Diener I, Puentedura EJ (2015a) The short term effects of preoperative neuroscience education for lumbar radiculopathy: A case series. International Journal of Spine Surgery 911. doi: 10.14444/2011. 
Louw A, Louw Q, Crous LCC (2009) Preoperative education for lumbar surgery for radiculopathy. South African Journal of Physiotherapy 65(2);38. doi: 10.4102/sajp.v65i2.244.

Louw A, Puentedura E (2014) Therapeutic neuroscience education, pain, physiotherapy and the pain neuromatrix. International Journal of Health Sciences 2(3):33-45. doi: 10.15640/ijhs.v2n3a4.

Louw A, Puentedura EJ, Diener I, Peoples RR (2015b) Preoperative therapeutic neuroscience education for lumbar radiculopathy: a singlecase fMRI report. Physiotherapy Theory and Practice 31(7):496-508. doi: 10.3109/09593985.2015.1038374.

Meeus M, Nijs J, Van Oosterwijck J, Van Alsenoy V, Truijen S (2010) Pain physiology education improves pain beliefs in patients with chronic fatigue syndrome compared with pacing and self-management education: a double-blind randomized controlled trial. Archives of Physical Medicine and Rehabilitation 91 (8):1153-1159. doi: 10.1016/j.apmr.2010.04.020.

Moseley GL (2003a) Joining forces - combining cognition-targeted motor control training with group or individual pain physiology education: a successful treatment for chronic low back pain. Journal of Manual and Manipulative Therapy 11(2):88-94. doi: 10.1179/106698103790826383.

Moseley GL (2003b) Unravelling the barriers to reconceptualisation of the problem in chronic pain: the actual and perceived ability of patients and health professionals to understand the neurophysiology. Journal of Pain 4(4):184-189. doi: 10.1016/S1526-5900(03)00488-7.

Moseley GL (2005) Widespread brain activity during an abdominal task markedly reduced after pain physiology education: fMRI evaluation of a single patient with chronic low back pain. Australian Journal of Physiotherapy 51(1):49-52. doi: 10.1016/S0004-9514(05)70053-2.

Moseley GL (2007) Reconceptualising pain acording to modern pain sciences. Physical Therapy Reviews 12:169-178. doi: 10.1179/108331907X223010.

Moseley GL, Nicholas MK, Hodges PW (2004) A randomized controlled trial of intensive neurophysiology education in chronic low back pain. The Clinical Journal of Pain 20(5):324-330.

Moseley L (2002) Combined physiotherapy and education is efficacious for chronic low back pain. Australian Journal of Physiotherapy 48(4):297-302. doi: 10.1016/S0004-9514(14)60169-0.

Nijs J, Crombez G, Meeus M, Knoop H, Damme SV, Cauwenbergh V, Bleijenberg $G$ (2012) Pain in patients with chronic fatigue syndrome: time for specific pain treatment? Pain Physician 15(5):E677-686.

Nijs J, Paul van Wilgen C, Van Oosterwijck J, van Ittersum M, Meeus M (2011) How to explain central sensitization to patients with 'unexplained' chronic musculoskeletal pain: Practice guidelines. Manual Therapy 16(5):413-418. doi: 10.1016/j.math.2011.04.005.
Nijs J, Roussel N, Paul van Wilgen C, Koke A, Smeets R (2013) Thinking beyond muscles and joints: therapists' and patients' attitudes and beliefs regarding chronic musculoskeletal pain are key to applying effective treatment. Manual Therapy 18(2):96-102. doi: 10.1016/j. math.2012.11.001.

Nijs J, Van Houdenhove B (2009) From acute musculoskeletal pain to chronic widespread pain and fibromyalgia: application of pain neurophysiology in manual therapy practice. Manual Therapy 14(1):3-12. doi: 10.1016/j. math.2008.03.001

Oshodi TO (2007) The impact of preoperative education on postoperative pain. Part 1. British Journal of Nursing 16(12):706-710.

Ostelo RW, de Vet HC, Vlaeyen JW, Kerckhoffs MR, Berfelo WM, Wolters PM, van den Brandt PA (2003) Behavioral graded activity following first-time lumbar disc surgery: 1-year results of a randomized clinical trial. Spine 28(16):1757-1765.

Puentedura EJ, Brooksby CL, Wallmann HW, Landers MR (2009) Rehabilitation following lumbosacral percutaneous nucleoplasty: a case report. Journal of Orthopaedic and Sports Physical Therapy 40(4):214-224. doi: $10.2519 /$ jospt.2010.3115.

Sandberg J, Barnard Y (1997) Deep learning is difficult. Instructional Science 25(1):15-36. doi: 10.1023/a:1002941804556.

Sloan TJ, Walsh DA (2010) Explanatory and diagnostic labels and perceived prognosis in chronic low back pain. Spine 35(21):E1120-1125. doi: 10.1097/BRS.0b013e3181e089a9.

Wall PD, Melzack R (1999) Textbook of Pain (4th edn). Edinburgh: Churchill Livingstone.

Wittmann-Price RA, Godshall M (2009) Strategies to promote deep learning in clinical nursing courses. Nurse Education 34(5):214-216. doi: 10.1097/ NNE.0b013e3181b2b576.

Woolf CJ (2007) Central sensitization: uncovering the relation between pain and plasticity. Anesthesiology 106(4):864-867. doi: 10.1097/01. anes.0000264769.87038.55.

Woolf CJ, Salter MW (2000) Neuronal plasticity: increasing the gain in pain. Science 288(5472):1765-1769.

Zimney K, Louw A, Puentedura EJ (2014) Use of Therapeutic Neuroscience Education to address psychosocial factors associated with acute low back pain: a case report. Physiotherapy theory and practice 30(3):202-209. doi: 10.3109/09593985.2013.856508. 